\title{
Effect of Ta on the wear behavior of Laser Cladding Ni60 Alloy Coatings FU Wei ${ }^{1,2, a}$, YONG Yaowei ${ }^{3,4, b}$, YU Ting ${ }^{3, c}$, DENG Qilin ${ }^{3, d_{*}}$
}

1. State Key Lab of Advanced Welding and Joining, Harbin Institute of Technology, Harbin, 150001, PR China

2. BAOSTEEL Industry Technological Service Co., Shanghai, Ltd, 201900, PR China

3. School of Mechanical Engineering, Shanghai Jiao Tong University, Shanghai, 200240, PR China

4. School of Mechanical Engineering, Ningxia University, Yinchuan Ningxia, 750021, PR China

a fw9106@163.com, ${ }^{b}$ yywnxu@163.com, ${ }^{c}$ yuyeting@sina.com, ${ }^{d}{ }^{*}$ dengqilin@sjtu.edu.cn

Keywords: laser cladding; Ni60 alloy; Tantalum; TaC

\begin{abstract}
Ni60 coating provides excellent hardness and wear resistance, it is usually used to strengthen the parts worked the severely conditions with intensified friction. While Ni60 has a strong crack susceptibility due to its high brittleness and high thermal gradient in transient cladding process. In order to improve the wear resistance of Ni60 coating, the strong carbide forming element is introduced. Among those elements, Tantalum (Ta) is a typical element, it exhibits an excellent chemical inertness, which is an important property in laser cladding. The wear behaviors of Ni60+Ta.wt\% composite coating are studied. The results show that Ta improves the toughness of Ni60 composite coating and sliding and abrasive wear resistance while decrease the crack susceptibility.
\end{abstract}

\section{Introduction}

Ni60 coating provides excellent hardness and wear resistance, which is used to strengthen the parts under the adverse conditions of intensified friction, for example, the working surface of continuous casting crystallizer is strengthened by Ni60. While Ni60 has a strong crack susceptibility due to its high brittleness and high thermal gradient in transient cladding process[1]. $M_{7} C_{3}$ carbide is the main strengthening phase in Ni60 coating and more carbon in the coating, which means more carbide in alloy, can improve the hardness and wear resistance of the coating. $\mathrm{M}_{7} \mathrm{C}_{3}$ will grow coarse as carbide content increases, the length of the $\mathrm{M}_{7} \mathrm{C}_{3}$ can reach to $180 \mu \mathrm{m}$ with large aspect ratio. The amount of coarse carbide improves the coating hardness and crack sensitivity while high stress concentration be caused by rapid cooling, so the crack is easily initialized and propagated under the friction and thus the spalling is occurred [2]. In addition, the coarse hard phase is easy to fracture under the high stress friction, therefore, debris will fall between friction surface and become grits, which will accelerate the wear of materials [3].

In order to improve the wear resistance of materials, researchers constantly develop new materials or improve existing materials to meet the demand. Since strong carbide forming elements (such as Ti, $\mathrm{V}, \mathrm{Zr}$, etc.) and $\mathrm{C}$ elements can form MC carbides with good hardness, high elastic modulus and high chemical stability, in recent years, extensive studies [4-6]in situ synthesized MC carbides (such as $\mathrm{TiC}, \mathrm{VC}, \mathrm{ZrC}$ ) had been conducted to strengthen coating. Among those studies, TiC had been paid more attentions. However, chemical properties of $\mathrm{Ti}$ is active, and it is easy to oxidize in air [7], moreover, there existed large amounts of porosity in the coating.

Wear-resisting performance of metal matrix composites (MMCs) is not only depend on reinforced particles hardness, shape, size, volume fraction, distribution of grains and the properties of the matrix, but also the bonding strength on interface between matrix and coating. The stronger bonding strength can ease micro-crack formation and expansion, therefore, particles are hard to escape from matrix, and embedded in the matrix for much time so as to protect material in the process of friction. The 
wettability between particles and matrix has important influence on the interface bonding strength, the smaller wetting angle is, and the higher bonding strength is. The melting point, hardness and wetting angle between Ni-based matrix of $\mathrm{MC}$ carbide formed by stronger carbide forming element are listed in Table $1[6,8,9]$. It can be found that the $\mathrm{TaC}$ has a lower hardness with highest melting point and smallest wetting angle.

Table.1 Melting point, hardness and wetting angle between Ni-based matrix of MC carbide

\begin{tabular}{cccccc}
\hline & $\mathrm{TiC}$ & $\mathrm{VC}$ & $\mathrm{ZrC}$ & $\mathrm{NbC}$ & $\mathrm{TaC}$ \\
\hline wetting angle $\left(^{\circ}\right)$ & 23 & 17 & 25 & - & 16 \\
Microhardness $\left(\mathrm{kg} / \mathrm{mm}^{2}\right)$ & $2580 \sim 3200$ & $2250 \sim 2950$ & $2560 \sim 2830$ & $2020 \sim 2400$ & $1500 \sim 1800$ \\
Melting Point $\left({ }^{\circ} \mathrm{C}\right)$ & 3067 & 2810 & 3532 & 3608 & 3880 \\
\hline
\end{tabular}

$\mathrm{Ta}$ is a strong carbide forming elements, it not only solid solution strengthen Ni metal, also react with $\mathrm{C}$ to form $\mathrm{TaC}$. Moreover, Ta has some excellent properties such as high chemical stability, slower reaction with oxygen in the air than $\mathrm{Ti}$, those are helpful for pore-free in the cladding without protection. Contributed to refine effect of Ta for $\mathrm{M} 7 \mathrm{C} 3$ particles and thus reduces crack sensitivity of Ni60 coating, the studies on the hardness and wear behaviors of in-situ TaC coating onto Ni60 have been conducted.

\section{Experimental procedure}

Vickers microhardness (model: MVC-1000A) was utilized to measure the hardness of cross section of the coating, the load was $300 \mathrm{~g}$ and load duration was $15 \mathrm{~s}$. Dry sliding wear tests were carried on MPX-2000 disc-on-pin and MM 200 block-on-ring tester at room temperature.

1) disc-on-pin wear test:

Principle of disc-on-pin wear tester is shown in Fig.1. Cladding specimens was cut to $18 \times \Phi 5 \mathrm{~mm}$, and the wear disk was machined to $10 \times \Phi 35 \mathrm{~mm}$. In process, the disc is in stationary while the loaded pin was pushed on the disk with turning radius of $10 \mathrm{~mm}$. In order to prevent the dilution in cladding coating, the multi-layer cladding was done on the substrate with about $2 \mathrm{~mm}$ thickness cladding, which is prepared for future sliding wear test.

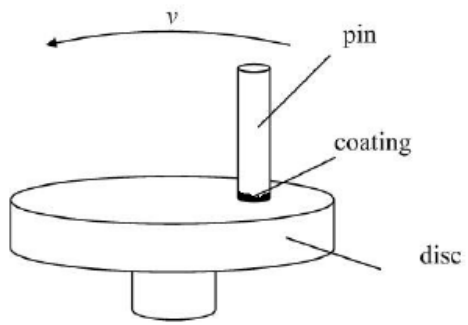

Fig.1 Principle of disc-on-pin

The couple wear disc is made of GCr15 with hardness of HRC62. In the previous of testing, the cladding surface and disc surface were ground with roughness about $0.6 \mu \mathrm{m}$. The specimens were then ultrasonically cleaned in alcohol for each test. The cladding pin was pressed on the rotated disc with turning radius of $10 \mathrm{~mm}$, the test sustained for one hour. The loss weight was obtained by digital balance with precision of $0.1 \mathrm{mg}$, the density of coating was then measured by electronic density meter with $1 \mathrm{mg} / \mathrm{cm}^{3}$ precision. Thus, the volume loss was calculated by ratio of weight loss to coating density, and the result was the average of 3 measurements.

2) Abrasive wear test

The $\mathrm{SiC}$ abrasive paper was stuck on disk plate and the cladded pin was pressed on the rotated disk. The turning radius is $10 \mathrm{~mm}$. In the process, the abrasive was changed every 1 minute, at same time, the pin should be cleaned by ultrasonically cleaner. When the wear test was finished, the loss weight was obtained by digital balance with precision of $0.1 \mathrm{mg}$, the density of coating was then measured by electronic density meter with $1 \mathrm{mg} / \mathrm{cm}^{3}$ precision. The volume loss was calculated by ratio of weight 
loss to coating density, and the result was the average of 5 measurements.

\section{Results}

Fig.2 shows the distribution of TaC particles in Ni60+7 wt.\%Ta composite coating.
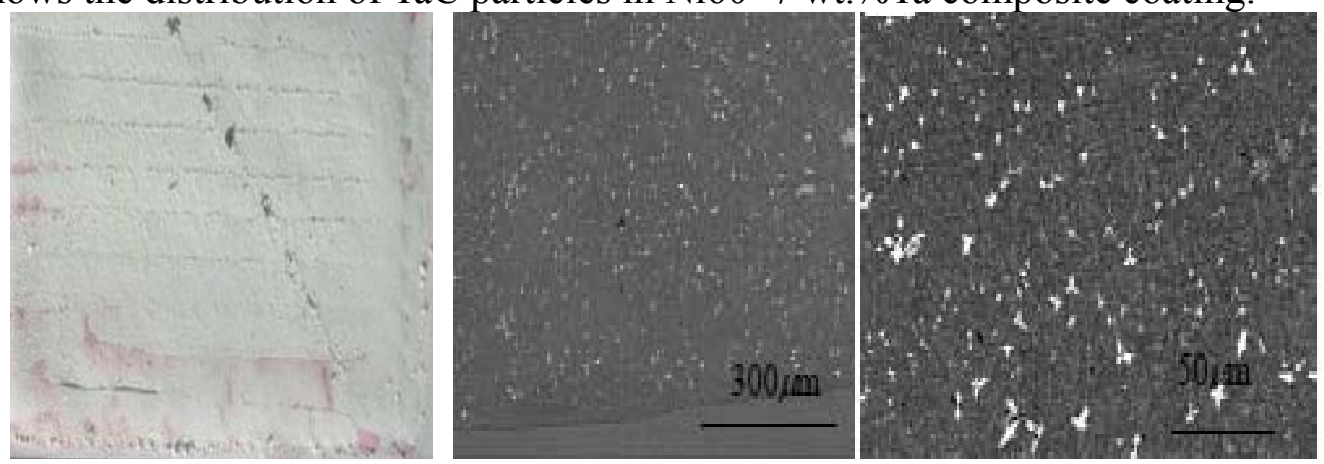

Fig 2 Distribution of TaC particles in Ni60+7 wt. \% Ta composite coating

a) Ni60+7 wt. \% Ta composite coating; b) low magnification of coating; c) high magnification of coating

The hardness distribution in cross section of the Ni60 alloy and different content of Ta particles reinforced Ni60 alloy composite coating are showed in Fig.3.

The weight loss, who has a proximately linear relationship with sliding time, compared with different Ta are shown in Fig.4, and the wear couple is SiC abrasive paper with 240 mesh.

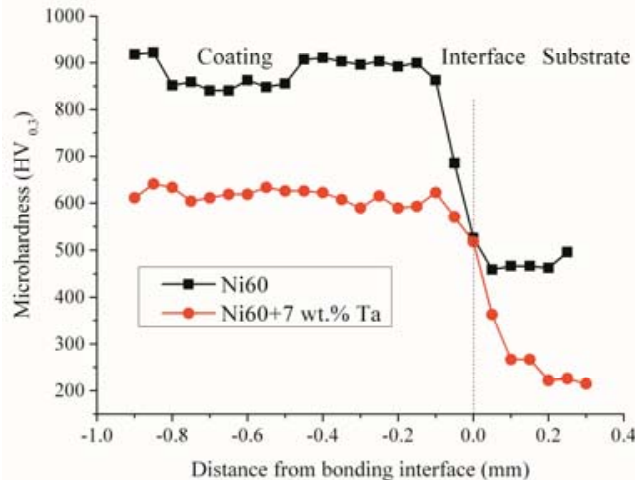

Fig 3

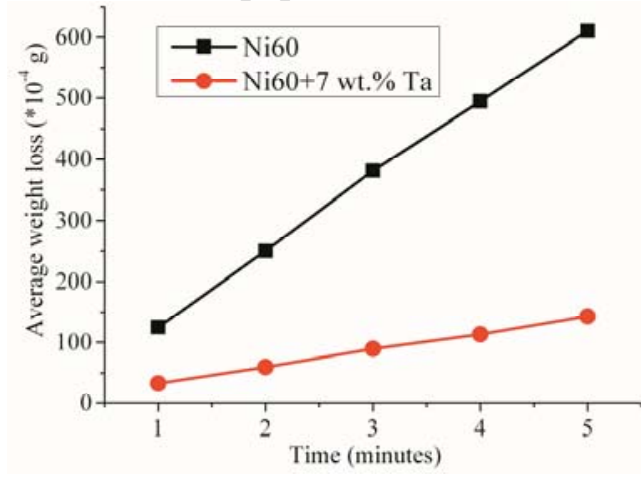

Fig4

The wear ratio of the Ni60 alloy and Ni60+7 wt.\%Ta composite coating are showed in Fig.5.Whileas the worn surface morphologies and EDS of Ni60 alloy and Ni60+7 wt.\%Ta composite coating are shown in Fig. 6 as the sliding speed is $0.4 \mathrm{~m} / \mathrm{s}$ and a load of $25 \mathrm{~N}$.

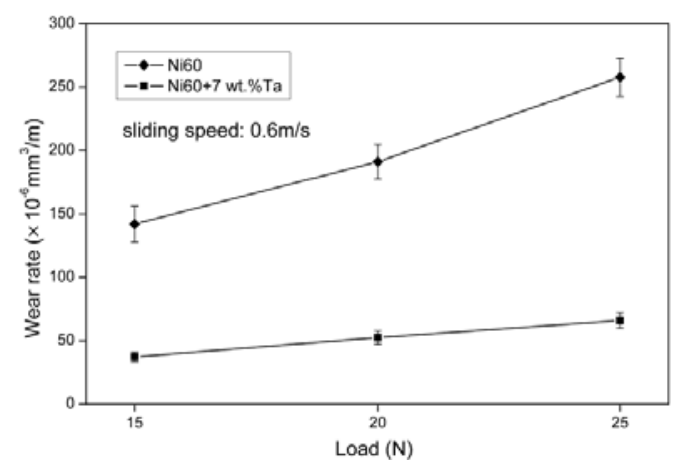

Fig.5 Wear ratio of the Ni60 alloy and Ni60+7 wt.\%Ta composite coating 

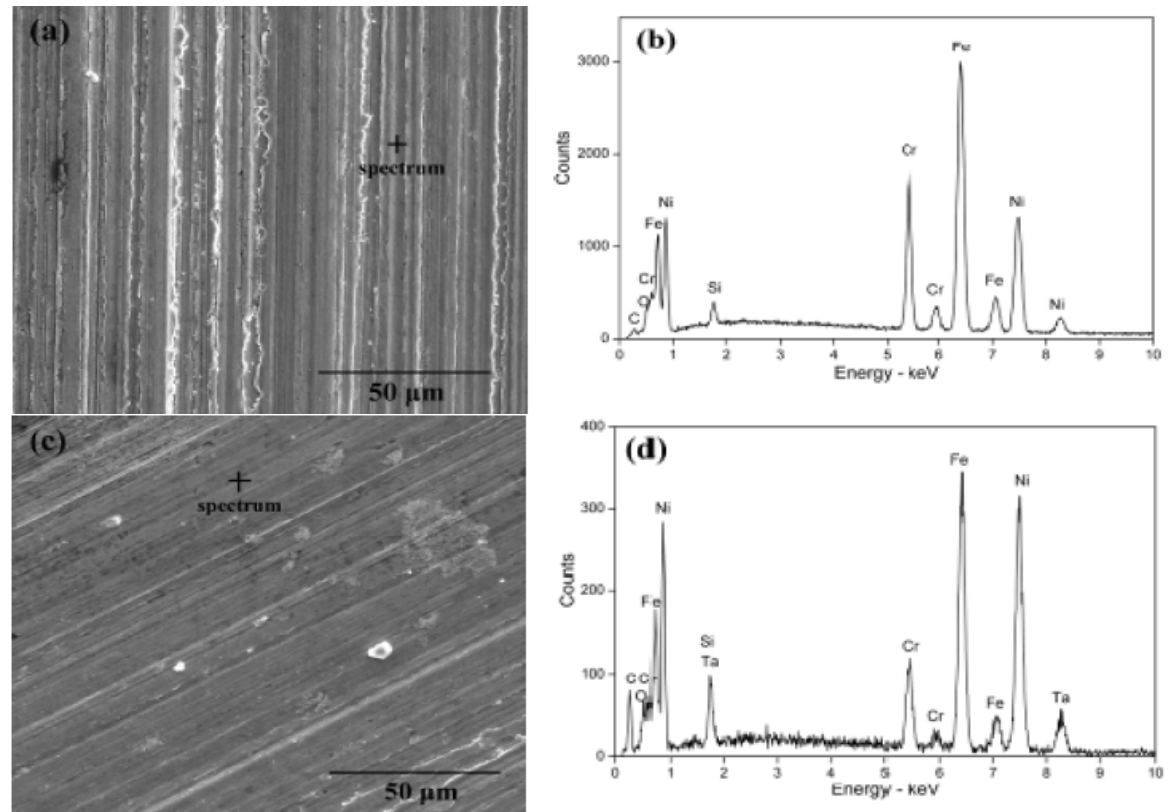

Fig.6 Worn surface morphologies and EDS of Ni60 alloy (a and b) and Ni60+7 wt. \%Ta(c and d) composite coating

In Fig.7, it shows the spalling phenomena in worn surface of Ni60 coating the sliding speed is $0.4 \mathrm{~m} / \mathrm{s}$ and a load of $25 \mathrm{~N}$. The back-scattered SEM of Ni60+7wt. \%Ta and Ni60+10wt. \%Ta are shown in Fig.8.

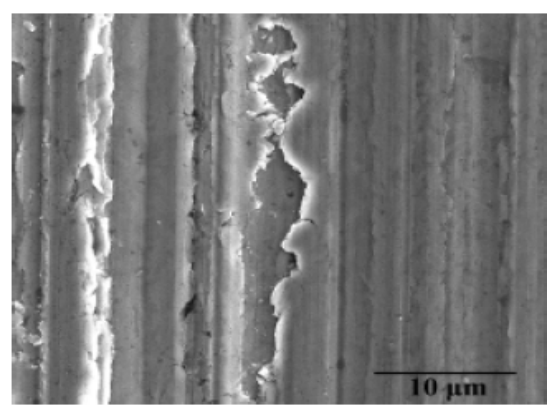

Fig.7 Spalling phenomena in worn surface of Ni60 coating
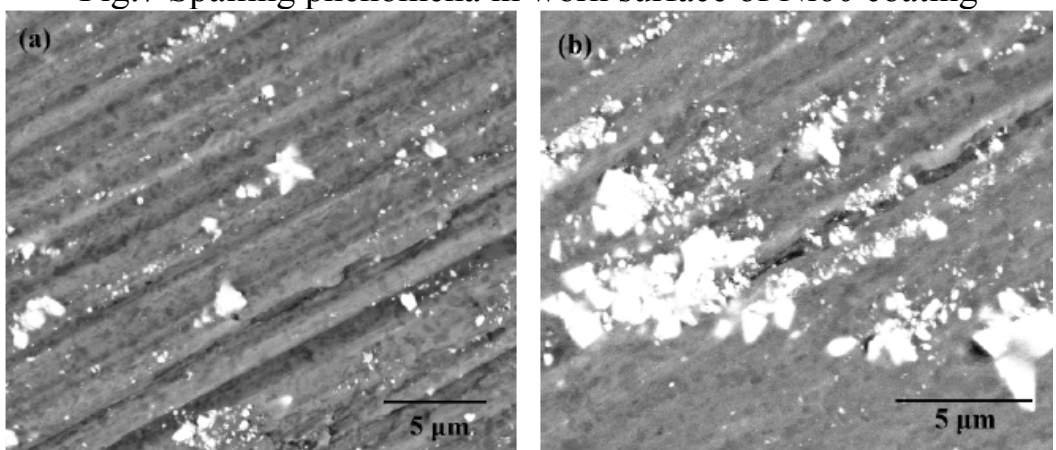

Fig.8 Back-scattered SEM of Ni60+7wt. \%Ta (a) and Ni60+10wt. \%Ta (b)

In dry sliding wear, the wear volume loss of Ni60 and Ni60+7wt. \%Ta composite coating with different load is shown in Fig.9. 


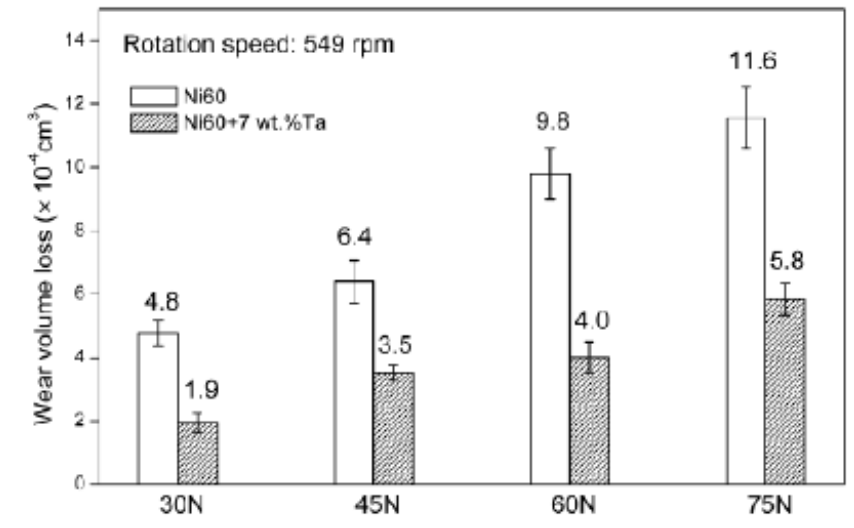

Fig.9 Wear volume loss of Ni60 and Ni60+7wt. \%Ta composite coating with different load

\section{Discussion}

The quality of Ni60+7 wt. \% Ta composite coating sounds good and free from cracks on its surface, in view of Fig.2, the TaC particles are distributed in coating is uniformed.

Figure 3 reveals that addition of Ta in mass causes the decline of coating hardness. The introduce of Ta can form TaC carbide in process, nevertheless, it also restrains growth of $\mathrm{M}_{7} \mathrm{C}_{3}$ and $\mathrm{M}_{23} \mathrm{C}_{6}$ due to the volume ratio of $\mathrm{TaC}$ and $\mathrm{M}_{7} \mathrm{C}_{3}+\mathrm{M}_{23} \mathrm{C}_{6}$ is a reciprocal relationship. Because the growth rate of $\mathrm{TaC}, \mathrm{M} 7 \mathrm{C} 3$ and $\mathrm{M}_{23} \mathrm{C}_{6}$ are different, which causes the difference between the increment of TaC and reduction of $\mathrm{M}_{7} \mathrm{C}_{3}+\mathrm{M}_{23} \mathrm{C}_{6}$ in volume. In fact, dendrite size of $\mathrm{M}_{7} \mathrm{C}_{3}$ in Ni60 is obviously larger than $\mathrm{TaC}$ particles in same conditions, which concludes that the $\mathrm{M}_{7} \mathrm{C}_{3}$ has larger growth rate in laser cladding. Therefore, it is hard to assert that the total carbide content is increased as the $\mathrm{Ta}$ is introduced due to the irregular shape or undersize of carbide, even more, it is difficult to calculate the change in carbide volume by image analysis, thus, the hardness deepened on carbide volume cannot be estimated. Whereas the relationship between hardness and content of Ta can be analyzed according the phase content and size in Ni-based matrix. Ta inhabits the growth of $\gamma-\mathrm{Ni}+\mathrm{M}_{23} \mathrm{C}_{6}$ eutectics, resulting in dendrite size of $\mathrm{Ni}$ in middle of coating increases from $1 \sim 5 \mu \mathrm{m}$ to $2 \sim 15 \mu \mathrm{m}$ and the phases of matrix become coarse obviously, the volume of Ni matrix is increased from $17.8 \%$ to $40.6 \%$. Coarse grain weakens the fine grain strengthening, accompanying with increased volume, the coating hardness is declined after introducing the Ta into coating.

Figure 4 reveals that weight loss has a linear relationship with sliding time. The additional Ta causes continual decrease in the weight loss of composite coating. The tendency of wear loss declines slowly as the mass of $\mathrm{Ta}$ is up to $10 \%$, and the wear loss is closed to Ni60+7 wt. \% Ta composite coating. The wear loss of pure Ni60 is about 4 times of that of Ni60+7 wt. \% Ta composite coating.

From the view of Fig.5, it can be found that the wear ratio of both coating increase with the improved load and show an approximately linear relationship. Whatever the wear condition be selected, the additional mass of Ta causes the decrease constantly, which means that Ta can improve the abrasive wear properties. When the load is $25 \mathrm{~N}$, the wear ratio of Ni60 coating is about 4 times of that of Ni60+7 wt. \% Ta composite coating.

The morphology of worn surface of Ni60 and Ni60+7 wt. \% Ta coating are shown in Fig.6. Due to the hardness of $\mathrm{TaC}$ carbide and $\mathrm{M}_{7} \mathrm{C}_{3}$ carbide is lower than that of $\mathrm{SiC}$ carbide, the cladding material provide only little resistance to the $\mathrm{SiC}$ particles for both coating. The parallel and continuous grooves are arising on both worn surface, and the dominant wear mechanism is cutting and ploughing. Compare the Fig.6a with Fig. 6 c, it is clear that the Ni60+7 wt. \% Ta worn surface of coating is smoother than that of Ni60, and the grooves in worn surface of Ni60 are deeper than that of Ni60+7 wt. \%Ta. And the EDS analysis (as shown in Fig.6 b and Fig.6 d) shows that the oxidation in worn surface of both coating is not excessive.

During the solidification, the high cooling rate in laser cladding produces high residual stress in coating, which will generate defects in microstructure such as cracks and pores. During the abrasive wear, the high cyclic contact stress inoculates micro-crack onto the Ni60 coating, who is 
characterized by high brittleness and hardness. However, those cracks propagate and spalls the material from coating, which is shown in Fig.7.The sloughy debris peeled from coating are detained between the sliding surface, and becomes abrasive grains to take part in wearing the specimens. The hardness of Ni60 coating is higher than that of Ni60+7wt. \% Ta composite coating and the fracture toughness is less than that of Ni60+7wt. \% Ta composite coating inversely, which means that the critical surface contact stress of Ni60 for fracture is lower. Those are the reasons why the spall phenomena of Ni60 coating is more severely and partially reasons why the wear resistance is weaker than that of Ni60+7wt. \% Ta composite coating.

Figure 8 shows that the width of grooves are close to or less than the TaC particle size, so the composite coating cannot be thought as homogenous material simply. $\mathrm{TaC}$, who has high hardness, large elastic modulus, withstands the high contact stress come from the abrasive grains in the wear process, therefore, the grooves on the surface of Ni60+7 wt.\% Ta composite coating are shallower than that of Ni60. Since SiC has a higher hardness than TaC sturdily bonded with matrix, it thus is not squeezed from matrix but crushed by abrasive grains under the high contact stress. The crushed $\mathrm{TaC}$ particles are embedded in the matrix, and thus protect the material.

Figure 8 shows that volume loss of $\mathrm{Ni} 60+7 \mathrm{wt}$. \% Ta composite coating is much lower than that of Ni60 under the same wear conditions in the dry sliding wear test. The loss volume of Ni60+7 wt. \% Ta composite coating is half of that of Ni60 coating, which means that Ta can improve the wear resistance under the dry sliding environment.

\section{Conclusion}

1. The quality of Ni60+7 wt. \% Ta composite coating sounds good and free from cracks on its surface, the $\mathrm{TaC}$ particles are distributed in coating is uniformed.

2. With the addition of $\mathrm{Ta}$, the hardness of Ni60+Ta is declined gradually, while the fracture toughness of Ni60 coating is improved.

3. Wear resistance of Ni60+7wt. \% Ta composite coating is improved about 4 times of that of Ni60 coating. As a particle reinforced composite material, the wear resistance of Ni60+7wt. \% Ta composite coating depends on the matrix and strengthening phase, but also the bond strength between particles phase and interface. Ta improves the toughness of coating and inhabits the propagation of crack in wear process. The solid solution strengthened phase can withstand in-situ synthesized $\mathrm{TaC}$ particles, who tightly combines with Ni60, and make the TaC particles not easy to fall off.

4. In dry sliding test, $\mathrm{TaC}$ particles tightly bond with the matrix, and the mechanism of wear is plough and micro-cutting, therefore, they suppress the cold welding in surface and improve, improve resistance of plastic deformation, as a result, the wear resistance of coating are thus improved. In high contact stress, $\mathrm{TaC}$ is crushed and embedded into the matrix and hence as a hard particle to support wear couple and extend the life.

\section{Acknowledgment}

The authors gratefully thank the financial support from National Natural science foundation of China (No 51275303)

\section{References}

[1] T. Yu, Q.L. Deng, W. Zhang, G. Dong, J.G. Yang, Shanghai Jiaotong Daxue Xuebao/Journal of Shanghai Jiaotong University, 46 (2012) 1043-1048.

[2] H. Zhang, Y. Shi, M. Kutsuna, G.J. Xu, Nuclear Engineering and Design, 240 (2010) 2691-2696.

[3] W. Xiaolei, C. Guangnan, TRANSACTIONS OF METAL HEAT TREATMENT, 20 (1999) 20-25+49. 
[4] L. Chen, Y. Liu, H. Tang, H. Liu, Y. Huang, Xiyou Jinshu Cailiao Yu Gongcheng/Rare Metal Materials and Engineering, 34 (2005) 1609-1612.

[5] Q. Zhang, J. He, W. Liu, M. Zhong, Surface and Coatings Technology, 162 (2003) 140-146.

[6] S. Hai-qin, C. Ming-ju, J. Xiao-ding, Z. Xian-hu, Laser Journal, 29 (2008).

[7] X.H. Wang, L. Cheng, M. Zhang, S.Y. Qu, B.S. Du, Z.D. Zou, Surface Engineering, 25 (2009) 211-217.

[8] R.J. Li, Ceramic-metal Composite, Metallurgical Industry Press, Beijing, 2004.

[9] D.R. Lide, Handbook of Chemistry and Physics, 11st ed., CRC Press, 2010. 